UCRL-ID-129846

\title{
Review of Existing Reactive Transport Software
}

\author{
W. E. Glassley, W. L. Bourcier, J. W. Johnson
}

Febuary 3, 1998

This is an informal report intended primarily for internal or limited external distribution. The opinions and conclusions stated are those of the author and may or may not be those of the Laboratory.

Work performed under the auspices of the U.S. Department of Energy by the Lawrence Livermore National Laboratory under Contract W-7405-Eng-48. 


\section{DISCLAIMER}

This document was prepared as an account of work sponsored by an agency of the United States Government. Neither the United States Government nor the University of California nor any of their employees, makes any warranty, express or implied, or assumes any legal liability or responsibility for the accuracy, completeness, or usefulness of any information, apparatus, product, or process disclosed, or represents that its use would not infringe privately owned rights. Reference herein to any specific commercial product, process, or service by trade name, trademark, manufacturer, or otherwise, does not necessarily constitute or imply its endorsement, recommendation, or favoring by the United States Government or the University of California. The views and opinions of authors expressed herein do not necessarily state or reflect those of the United States Government or the University of California, and shall not be used for advertising or product endorsement purposes.

This report has been reproduced directly from the best available copy.

Available to DOE and DOE contractors from the Office of Scientific and Technical Information

P.O. Box 62, Oak Ridge, TN 37831

Prices available from (615) 576-8401, FTS 626-8401

Available to the public from the

National Technical Information Service

U.S. Department of Commerce

5285 Port Royal Rd.,

Springfield, VA 22161 


\title{
Review of Existing Reactive Transport Software
}

\author{
William E. Glassley, William L. Bourcier, James W. Johnson \\ Lawrence Livermore National Laboratory
}

Livermore, CA 94550

\section{INTRODUCTION}

Simulations of thermal and hydrological evolution following the potential emplacement of a subterranean nuclear waste repository at Yucca Mountain, NV (e.g., Buscheck and Nitao, 1992, 1993a, b, 1994), provide data that suggest the inevitability of dependent, simultaneous chemical evolution in this system (e.g., Glassley, 1993). These chemical changes will modify significantly both the magnitude and structure of local porosity and permeability; hence, they will have a dynamic feedback effect on the evolving thermal and hydrological regime. Yet, despite this intimate interdependence of transport and chemical processes, a rigorous quantitative analysis of the post-emplacement environment that incorporates this critical feedback mechanism has not been completed to date. As an initial step in this direction, the present document outlines the fundamental chemical and transport processes that must be accounted for in such an analysis, and reviews the inventory of existing software that encodes these processes in explicitly coupled form. A companion report describes the prioritization of specific capabilities that are needed for modeling post-emplacement reactive transport at Yucca Mountain.

A myriad of experimental studies that couple water-rock interaction and transport through porous media have demonstrated the interdependence of chemical reaction and fluid transport. Physical manifestations of this coupling observed in the laboratory include complete healing of natural and synthetic fractures (Lin and Dailey, 1989), large decreases in permeability (up to 97\%) as a function of small reductions (a few percent) in the porosity of non-fractured rocks having initially low permeability and porosity (Camp, 1964; Scheidegger, 1974; Pearson, 1976; Brace, 1977; McClure et. al., 1979; Morrow et al., 1981; Keith et al., 1983; Vaughan, 1985; Moore et al., 1986; Pyrak-Nolte et al., 1987; Verma and Pruess, 1988; Lin and Daily, 1989), and substantial sealing of flow pathways in crushed material characterized by extremely large initial ratios of reactive surface area to fluid volumes (Rimstidt and Newcomb, 1989). In natural systems having thermal and hydrological regimes similar to those of the model simulations, complete sealing of fractured rocks overlying the driving heat source have been described (e.g., Krupp and Seward, 1987). All of these results suggest that heat and fluid transport within the altered zone of 
the repository block at Yucca Mountain may be affected significantly by on-going chemical evolution. The magnitude of this reaction-transport coupling is such that thermal-hydrological simulations that do not explicitly account for this effect are almost certainly incapable of providing reliable simulations of post-emplacement thermal and hydrological history.

Any quantitative model of thermal, hydrological, and chemical evolution at the Yucca Mountain site must provide explicit mathematical coupling of these processes and be encoded within a reliable software package. A model of this kind is essential in order to address repository design and performance issues (Issues 1.4, 1.5, 1.10, and 1.11 of the Site Characterization Plan), and for ESF design. Currently, there are several computer programs in the public domain that constitute such a reactive transport simulator. However, the rigor with which the codes address each of the coupled processes relevant to the repository block varies, depending upon the specific application envisioned by the developer. The extent to which each of these programs can satisfactorily address the specific needs of the altered zone task is addressed in this report. The modeling requirements that must be satisfied are diverse. Listed below are those major issues, and topics within them, that are most important for reactive transport modeling.

\section{Fluid Flow}

Heat transfer

Mass transfer

Dual porosity

Heterogeneous permeability/porosity matrix

Phase separation (boiling, unsaturated conditions, two-phase flow)

Changes in stress field

II. Chemistry

Multicomponent

Speciation

Mineral precipitation/dissolution, with and without kinetics

Sorption

Surface complexation

Ion exchange

Range of ionic strengths and activity coefficient models

Redox disequilibria

Solid solutions

Isotope systematics

Nucleation 


\section{Colloids}

III. Coupling

Change in porosity due to reactions (e.g., mineral dissolution and precipitation, change in mineral volume with hydration or dehydration, etc.)

Change in permeability with porosity

IV. Numerical Methods

Finite difference/element

Lagrangian/Eulerian reference frame

Adaptive girding

Scalable dimensional range (microns to kilometers)

\section{1-2-3 Dimensional}

V. Other Topics

Documentation

Proprietary

QA status

Verification/validation studies

Graphic Post-Processor

The following descriptions of the individual computer programs considered in this review are referenced to the subjects and topics listed above. It must be pointed out that the current limitations of numerical processors, the absence of well constrained models and theoretical constructs for certain flow and reactive transport problems, and the general absence of experimental studies against which codes can be tested, make it currently impossible to construct a code that embodies all of the needed capabilities. This review of existing codes provides a snapshot of what the current capabilities are.

\section{.. DESCRIPTIONS OF SELECTED REACTIVE TRANSPORT SOFTWARE}

The codes described below were selected for consideration on the basis of their availability, but the list is not exhaustive. Other codes do exist which are either proprietary, and thus not available for our use until quality assurance issues are resolved, are still in the development stages 
and not yet available for release, or have only recently been available to us. We also are certain that other codes are available of which we are not aware. As time goes on, other codes will be added to this list, as we become aware of them, and as they are made available to us.

The codes below are described in alphabetical order. Note that the equations used to solve for heat flow, fluid flow, and solute transport in all of the codes are quite similar. Hence, in the following discussions, a detailed presentation of them is only given in the first description (1DREACT). In the other descriptions, functions are presented only if they significantly differ from those in the synopsis of 1DREACT.

1DREACT: (Steefel, 1993; Steefel and Lasaga, 1994): This program is a comprehensive, onetwo-dimensional reactive transport simulator that accounts for single-phase advective, diffusive, and dispersive mass flux, conductive and convective heat flow, advective solute transport, kinetically controlled fluid-rock mass transfer along fracture surfaces, and permeability variations that arise from porosity changes caused by mineral precipitation/dissolution. 1DREACT necessarily incorporates a variety of simplifying assumptions; nevertheless, the program provides a versatile and convenient numerical laboratory for modeling reactive transport in hydrothermal systems with imposed thermal gradients associated with emplacement of a nuclear waste repository. Moreover, the current program represents a well-designed, rigorously tested, and clearly documented point of departure for future advancements.

L. Fluid Flow: 1DREACT models heat transport and fluid flow by simultaneous account of the conservation of thermal energy, which can be expressed as (Steefel and Lasaga, 1994)

$$
\rho_{m} C_{P, m} \frac{\partial T}{\partial t}=\nabla \cdot\left(\lambda_{m} \nabla T-\rho_{f} C_{P, f} \mathbf{u}_{t} T\right)
$$

and the fluid continuity equation, which is defined by (Steefel and Lasaga, 1994)

$$
\frac{\partial\left(\phi_{m} \rho_{f}\right)}{\partial t}=-\nabla \cdot\left(\rho_{f} u_{f} T\right)
$$

where $\rho$ refers to density, $C_{p}$ denotes isobaric heat capacity, $T$ stands for temperature, $t$ signifies time, $\lambda$ represents thermal conductivity, $\phi$ defines porosity, the subscripts $f$ and $m$ refer to the fluid phase and bulk medium, respectively, and the fluid flux, $\mathbf{u}_{f}$, is obtained from Darcy's law, which can be written as (Steefel and Lasaga, 1994) 


$$
\mathbf{u}_{f}=-\frac{k}{\mu_{f}}\left(\nabla P-\rho_{f} \mathrm{~g}\right)
$$

where $k$ denotes permeability, $\mu$ stands for dynamic viscosity, $P$ represents pressure, and $g$ is the gravity vector. As is common practice, these conservation and continuity equations reasonably neglect as second-order effects the potential thermal energy contributions from radioactive decay or chemical reactions and fluid mass contributions from hydration or dehydration reactions. The continuity equation is further simplified by presuming that the both the fluid and rock matrix are essentially incompressible, which leads to $\nabla \cdot \mathbf{u}_{f}=0$. Moreover, in the context of these equations the fluid phase is presumed to be pure $\mathrm{H}_{2} \mathrm{O}$, and its properties $\left(\rho_{f}, \mu_{f}\right.$, and $\left.C_{P_{1} f}\right)$ are evaluated using several approximations to more rigorous formulations. Again, these simplifications are typical (in fact, they are incorporated in most of the programs evaluated in this review) and not unreasonable.

1DREACT permits definition of up to six zones of distinct initial porosity (and permeability) in the model system. However, in its present configuration the code cannot model any aspects of twophase flow or variations in the stress field.

II. Chemistry: The reaction module of 1DREACT explicitly accounts for multi-component chemical systems, complexation reactions in the fluid phase, and surface-controlled mineral dissolution/precipitation kinetics. The conservation of solute mass is described by (Steefel and Lasaga, 1994)

$$
\frac{\partial\left(\phi_{m} U_{j}\right)}{\partial t}+\nabla \cdot\left(\mathbf{u}_{f} U_{j}-\mathbf{D} \nabla U_{j}\right)=R_{j}^{\min }
$$

where $U$, refers to the total solution concentration of the $j$ th chemical component (accounting for a primary $j$ th solute and the $N_{i} j$-bearing complexes), $u_{j} U_{j}$ and $\mathrm{D} \nabla U_{j}$ represent the advective and diffusive/dispersive fluxes, $\mathbf{D}$ stands for the dispersion/diffusion coefficient, and $R_{j}^{m i n}$ denotes the reaction rate term, which is the product $v_{j, m} r_{m}$ summed over the $N_{m}$ minerals, where $v_{j, m}$ refers to the stoichiometric coefficient of the $j$ th primary solute in the $m$ th mineral and $r_{m}$ is the precipitation/dissolution rate for that mineral. The surface-controlled kinetic rate is given by (Steefel and Lasaga, 1994) 


$$
r_{m}=\operatorname{sgn}\left(\log \left[\frac{Q}{K}\right]\right) A_{m} k_{m}\left|K^{-1} \prod_{j=1}^{N_{j}}\left(\gamma_{j} C_{j}\right)^{v_{j m}}\right|
$$

where $K$ refers to the aqueous dissolution constant for the $m$ th mineral, $Q$ stands for the associated ion activity product (defined by the numerator of the product term), $\gamma_{j}$ signifies the activity coefficient of the subscripted primary solute, $A_{m}$ denotes the reactive surface area, and $k_{m}$ is the reaction rate constant, whose temperature dependence is accounted for by an Arrhenius equation (Steefel and Lasaga, 1994):

$$
r_{m}=k_{25} \exp \left(-\frac{E_{a}}{R}\left[\frac{1}{T}-\frac{1}{298.15}\right]\right)
$$

where $r_{25}$ is the rate constant at $25^{\circ} C, E_{a}$ represents the activation energy, $R$ stands for the gas constant, and $T$ denotes temperature (in Kelvin).

Similar to the transport equations, these specific statements of solute-mass conservation and the kinetic rate law are obtained following several simplifying approximations: all complexation (homogeneous) reactions are considered reversible (i.e., local equilibrium is imposed on the fluid phase; hence, there is no provision for treating redox disequilibria), the dispersion/diffusion coefficient of each aqueous solute is considered identical, and the rate laws are strictly linear and do not account for the inhibiting or catalyzing effect of specific aqueous solutes. With the possible exception of uniformly reversible complexation reactions, these approximations are not terribly restrictive. Moreover, the kinetic description avoids imposition of the local equilibrium constraint on fluid-rock (heterogeneous) reactions, there is no theoretical limit to the number of chemical components and species that can be considered, and the nucleation process associated with mineral precipitation is explicitly accounted for (supersaturation catalyzes "instantaneous" growth of a 10micron radius crystal). In addition, it is possible to run IDREACT using both standard and customized thermodynamic databases.

The present release of IDREACT does not explicitly account for the effects of sorption, colloids, ion exchange, or solid solutions. Also, because the program calculates activity coefficients from an extended Debye-Hückel formulation, it's range of applicability is limited to systems characterized by relatively dilute aqueous solutions.

III. Coupling: Temporal variations in the volume fraction of specific minerals as a function of irreversible dissolution/precipitation are explicitly accounted for with 


$$
\frac{\partial \phi_{m}}{\partial t}=V_{m} r_{m}
$$

where $V_{m}$ refers to the standard molal volume of the subscripted mineral, and used to calculate the dependent change in porosity from

$$
\phi=1-\sum_{m=1}^{N_{m}} \phi_{m}
$$

By assuming an idealized permeability structure composed of three mutually orthogonal sets of smooth parallel fractures having uniform aperture $\delta$ and spacing $d$ (isotropic permeability), the functional relationship between flow porosity, $\phi_{F}$, and permeability, $k$, can be defined as (Phillips, 1991)

$$
k=\frac{\phi_{F} \delta^{2}}{36} \text {, }
$$

where $\phi_{F}=\delta / d$, and variations in $\phi_{F}$ as a function of $\phi$ are restricted to the those affecting fracture aperture.

This relationship among permeability, porosity, and dissolution/precipitation incorporates another key simplifying assumption beyond those already noted for the fracture network; namely, all mineral dissolution/precipitation is restricted to the fracture surfaces themselves (i.e., reactioncontrolled porosity changes within the rock matrix are not accounted for; hence, this matrix is effectively impermeable from a chemical standpoint). This approximation leads to the constraint that the sum of mineral surface areas must equal the total surface area of rock in contact with the fluid. In sum, these permeability-structure and reaction assumptions create a permeabilityporosity-reaction model that is significantly reduced in complexity relative.to that which holds in natural systems; however, as noted by Steefel and Lasaga (1994), such simplification is unavoidable at the current stage of theoretical development. Moreover, even this idealized model can be used effectively to address the first-order effects of permeability evolution that results from mineral dissolution/precipitation in reactive flow systems.

IV.Numerical Methods: 1DREACT discretizes the partial differential equations that represent the transport and reaction processes using an integrated finite difference scheme (Steefel and Lasaga, 
1994; Steefel, 1993; Marsily, 1986; Patankar, 1980), and employs a one-step or "global implicit" method to solve the coupled nonlinear transport and reaction equations simultaneously (Kee et al., 1985). As discussed by Steefel and Lasaga (1994), there are pros and cons to these choices as well as several alternatives. The principal advantage of the integrated finite difference method is that variable grid spacing (which permits dynamic adaptive girding) and fluid velocities are readily incorporated. Moreover, in 1DREACT this method is implemented using Patankar's (1980) "power--law" scheme for the transport terms, which ensures that the appropriate (upwindweighted or fully-centered) difference formulation is used depending on the relative importance of advective and dispersive/diffusive transport. The one-step solution method has two important potential advantages relative to the alternative two-step strategies: first, the global convergence properties of this method are at times superior, and second, in the typical case where a wide range of reaction rates must be accounted for, it is often possible to take larger time steps for a given numerical-stability tolerance.

The numerical methods used in 1DREACT permit incorporation of many useful features that facilitate enhanced numerical stability, run-time performance, and modeling flexibility; these include dynamically calculated time steps, adaptive girding, and basis (i.e., primary solute) species switching, as well as the option to run the program in either transient or stationary--state mode. In transient mode, mineral volume fractions and surface areas are held constant for the duration of each time step; in stationary-state mode, these mineral properties are held constant until the solute concentrations achieve a quasi-stationary state (Lichtner, 1988, 1992). The latter option is an efficient method for modeling systems where the rate of variation in mineral properties is much slower than the rate at which solute concentrations achieve a stationary state (Steefel, 1993).

IDREACT can be used to conduct both one- and two-dimensional simulations. There are no restrictions with regard to the physical scales which can be represented. In this regard, note that in situations where the relative reaction rates of minerals can be considered constant, it is possible to perform scale transformations on the simulation results (Lichtner, 1993).

V.Other Topics: An excellent user's manual is available for IDREACT (Steefel, 1993). To date, the code has been used to address the local equilibrium approximation and porosity-permeability relationships in hydrothermal systems (Steefel and Lasaga, 1994), as well as the quantitative differences between fluid-rock reactions in advective- and diffusive-dominant environments (Steefel and Lichtner, 1994). Program development is on-going, and the code is not proprietary at present. 
Basin2: (Bethke, 1985; Bethke et al., 1993) Basin2 is a numerical model developed to trace through time the evolution of ground water regimes within sedimentary basins. It therefore is unique with respect to the other codes described in this document in that it is meant to be applied over a larger spatial area and evolve over longer time periods. However, Basin2 uniquely combines some features of fluid flow and chemistry that could be useful for modeling some key aspects of the hydrology of Yucca Mountain.

LEluid Flow: Basin2 uses a finite-difference technique to solve the fluid and heat flow and transport equations. It is formulated in Lagrangian coordinates and considers twodimensional flow in heterogeneous, anisotropic, and accreting domains. The user supplies a description of the finite difference grid and boundary conditions over which the calculation is performed. Basin 2 can simulate flow through an unlimited number of strata that can variable longitudinal hydrologic and lithologic properties. Faults can also be included in the grid.

The code takes into account density and heat capacity variations of the rock and fluid as a function of pressure-temperature conditions. It also accounts for density and heat capacity change of the fluid with salinity variations. Fluid viscosity values are generated internally using a look-up table based on data in (Phillips et al., 1981). The stress field generated during compaction is also calculated and used to predict porosity changes based on the simple empirical relation:

$$
\phi=\phi_{0} e^{-\beta \sigma_{4}}+\phi_{1}
$$

where $\phi_{0}$ is the initial reducible porosity, $\phi_{1}$ is the irreducible (final) porosity, $\beta$ is the compressibility of the reducible pore volume, and $\sigma_{e}$ is the effective stress (Bethke et al., 1993). Permeability is then calculated from porosity using the relationship:

$$
\log k_{\mathrm{x}}=A \phi+B \text {. }
$$

where $k_{x}$ is the permeability in the $\mathrm{x}$-direction, and $\mathrm{A}$ and $\mathrm{B}$ are empirical fitting parameters. The user defines the permeability in the $z$ direction as a simple function of $k_{x}$. The user also defines the heat flow into or out of the basin along all the boundaries.

IIII. Chemistry and Coupling: Two simple methodologies to couple fluid chemistry with flow are used in Basin2. Built into Basin2 are solubilities of 4 silica polymorphs (quartz, chalcedony, cristobalite, amorphous silica) and calcium sulfate (anhydrite). The solubilities of these phases are assumed to be a function of temperature only (for silica) and temperature and pressure (for anhydrite). The code computes the saturation state for these phases in each finite difference volume and adjusts the amount of phase present to insure 
saturation. Equilibrium is assumed at all locations. The code then updates the porosity and permeabilities based on the relationships above for the subsequent fluid flow calculation.

A more general method for coupling mineral precipitation/dissolution to fluid flow makes use of the chemical modeling code React. A React simulation for the appropriate fluid composition is carried out over the temperature range of the basin. React calculates the amounts of mineral phases present at each temperature using a rigorous speciation calculation. Basin2 is then linked to React using interface tables generated by React. In each finite difference element, Basin2 assumes equilibrium of secondary mineral phases with host fluid based on the masses listed in the React output file. The rock porosity and permeability is adjusted appropriately.

Although each of these approaches is based on reasonable assumptions regarding local equilibrium in basins, no reaction kinetics are considered. Also, neither of these approaches is consistent with a rigorous mass balance for elements. If a mineral is calculated to be supersaturated, it is allowed to be present regardless of whether sufficient mass is present to form it. All the mass may have been used up in precipitating minerals in adjacent elemental volumes.

IV. Numerical Methods: Basin2 solves the equations describing flow through a deforming medium using a finite difference technique (Bethke, 1985). It works with a curvilinear coordinate system that follows basin stratigraphy. This approach maintains an axis of the coordinate system that is parallel to the direction of greatest permeability. This approach introduces a small but finite error into the calculation. Basin2 automatically adjusts the time step of the flow calculation based on criteria involving the amount of sediment produced, the size of the last time step, and limiting maximum values for changes in temperature, pressure and salinity during the step.

V.Other Topics: In order to apply Basin2 to hydrologic problems at Yucca Mountain, some of the features of the code that are irrelevant must be turned off. These include features such as erosion and uplift rates, rock compaction, sedimentation rates, and a few others. This can be done by choosing appropriate input parameters.

Basin2 contains three algorithms for calculating the extent of reaction of organic materials. Although developed to predict petroleum generation, it may be simple a matter to modify the kinetic relations to be useful in modeling the alteration of organic matter (such as diesel fuel) present in the vicinity of the waste package.

Basin2 also has an excellent graphics post-processor that can be used to visualize the numerical results. 
Basin2 is documented in a 225 page users manual (Bethke, et al., 1993) and several publications from the literature (Bethke, 1985); Bethke, 1986; .Bethke et al., 1988). There have been no explicit verification/validation studies performed with the code, but there is a test library of simulations that could be used for that purpose. The code is a commercially available product, and cannot be modified at will without the consent of the owner.

FEHM: FEHM is a finite element code used in a variety of applications (Zyvoloski,1983, 1986; Zyvoloski, et al., 1988; Zyvoloski and Dash, 1991). This code was designed to describe heat and mass transfer in porous media, as may be encountered in hydrothermal systems and nuclear waste repositories. It's application has primarily been in evaluation of transport problems in the hot-dry rock project, and the Yucca Mountain Site Characterization Project's performance assessment efforts. Much of this work is in the process of being documented, and is not referencable.

L. Fluid Flow: Heat and mass transfer are explicitly considered in the code. Heat budgets during boiling are accounted for through thermodynamic functions that describe the properties of water. A temperature-dependent Henry's law treatment of dissolved species accounts for partitioning between liquid and vapor phases. Saturation conditions are explicitly calculated at each time step. The user determines how often output for these parameters is retrieved. Humidities are not part of the current output file, but are calculated internally and can be readily included. Boiling, unsaturated conditions, and two-phase flow are provided for. Dual porosity flow regimes, as well as equivalent continuum approaches, are options. These are selected by the user when a simulation is initialized. Fluid velocities are not currently explicitly provided in the output files. However, velocities are implicitly considered in the computational scheme. Explicit listing of velocities can be added to the code. The stress state is updated with each time step, or at appropriate time steps, depending upon the rate of change of stress. The code is designed to account for changes in heat transfer as stress conditions change. The code is also designed to evaluate effects of physical changes on stress state, using either a linear porosity deformation model, or a Gangi stress model.

I. Chemistry: Reaction kinetics are incorporated via a forward and reverse rate law for each reversible reaction describing the behavior of each species. The effective rate law for each reaction is then represented by

$$
\partial\left[S_{j}\right] / \partial t= \pm a_{j}\left\{k_{f o r} \prod_{i=1}^{m}\left[S_{i}\right]^{b(i)}-k_{r e v} \prod_{i=m+1}^{n}\left[S_{i}\right]^{b(i)}\right\}
$$


where $S_{j}$ is the concentration of solute species $j, S_{i}$ is the concentration of $j$ in reactant species 1 through $m$ and in product species, $m+1$ through $n, b(i)$ is the appropriate exponential for the forward or reverse reaction, $a_{j}$ is the stoichiometric coefficient, and the $k$ terms are the forward (for) and reverse (rev) rate constants for the appropriate reactions. Temperature dependence of the rate constants is derived from the Arrhenius expression

$$
k=A \exp (-\mathrm{E} / \mathrm{RT})
$$

where $A$ is the pre-exponential factor, $E$ is the activation energy, $R$ is the gas constant, and $T$ is temperature, in degrees Kelvin. Similar laws are used for the kinetics applied to sorbed species (discussed below), but concentrations are defined in terms of bulk rock density, fluid density, porosity, and specific isotherm parameters.

The code relies on user-defined reactions to describe the rates of reactions, and reaction stoichiometry. The net reaction, defining the speciation state for each species, is determined from the sum of the forward and reverse reactions. Temperature dependence of the reactions is accounted for via the rate expressions described above. The code can currently handle up to ten species. Activity coefficient models are not employed in the code; activity is assumed to be equivalent to concentration. Further code modifications are in progress to increase the total number of species that can be considered.

Sorption isotherms can be computed using Langmuir or modified Freundlich approaches. The kinetics of sorption can be included, in which case forward and reverse rates are user specified.

III. Coupling: Effect of dissolution and precipitation on porosity, permeability, and mechanical properties: The code is not currently designed to change porosity or permeability as dissolution or precipitation occur. However, a version of the code has been used in which user-defined and constructed modules were employed to make changes in porosity and permeability as dissolution or precipitation occurred (Robinson and Glassley, 1995, in prep.). Modification of the code to explicitly account for the impact of dissolution and precipitation on porosity and permeability, at appropriate time steps, is in progress. The code is not currently designed to deal with the effects of permeability and porosity on mass transfer although, as with the effect of dissolution and precipitation on porosity and permeability, user-defined modules have been developed to consider this effect (Robinson and Glassleý, 1995, in prep.). Full coupling of these processes will be incorporated in a new version of the code.

IV. Numerical Methods: The code is fully two-dimensional and three-dimensional. An automatic finite-element mesh generator is available for use with the code. Non-orthogonal meshes can be 
used. The cell dimensions for each lithologic unit are independent of those from other units. The user defines the region to be considered in terms of blocks. A given block then uses the same type of element, although element size may vary within the block, depending upon the calculational needs. For two-dimensional simulations, 4-noded quadrilaterals or 3-noded triangles can be used as elements, while three-dimensional simulations can use 8-noded hexahedrons or 6 noded triangular prisms. Properties of individual lithologic units can be included, and permeability anisotropy accounted for. The standard model employed for YMSCP simulations is on the scale of kilometers. However, simulations of mineralogical systems on the scale of millimeters or microns seems possible, provided the distribution of properties is not too complex. This situation, however, still needs to be evaluated, because of potential numerical problems at locations where dramatic changes in chemistry occur due to contrasting mineralogy.

Y. Other Topics: A users manual, in draft form, is available, and documents describing application of the code to different problems can be obtained. The code is undergoing a verification/certification process. It is not proprietary.

LEHGC: The LEHGC code (Lagrangian-Eulerian-HydroGeochemical-Code) is an enhanced version of the HYDROGEOCHEM code (Yeh \& Tripathi, 1990) The major improvement over HYDROGEOCHEM is that the numerical solution procedure has been modified to implement elements of the Lagrangian approach for the advective component of transport. This hybrid Lagrangian-Eulerian scheme allows larger time steps to be used in advection-dominated calculations and causes less numerical dispersion than traditional Eulerian schemes. LEHGC retains most of the features of HYDROGEOCHEM, which are described in most detail in the manual for that code (Yeh \& Tripathi, 1990)

LFluid Flow: LEHGC is a two-dimensional finite element code that provides for fluid advection and dispersion/diffusion. The elemental grid can be a homogeneous porous media or can account for discrete fractures. It can also provide for heterogeneous and anisotropic media. In all cases, it provides for saturated/unsaturated flow conditions. Because there is no heat transport considered in this code, it cannot account for boiling or any type of two-phase behavior for water. The relationship between moisture content and pressure head must therefore be supplied by the user. There is no provision for stress fields generated during reactive transport.

II. Chemistry LEHGC incorporates a very comprehensive chemical model. It currently provides for aqueous complexation, adsorption/desorption, ion exchange, precipitation/dissolution, redox 
reactions, and acid-base reactions. Redox reactions and acid-base reactions are essentially a special case of aqueous complexation reactions.

The speciation algorithm is a conventional one that uses the total analytical concentration of each element as the primary dependent variable. The total amount of element is divided up between those fractions in solution as free or complexed species, as adsorbed species, ion exchanged species, and as precipitated solids. This calculation is constrained by the mass action equations that describe these equilibria. Local equilibrium is assumed at all points along the reaction, that is, all these reactions are assumed to be at equilibrium throughout the system. No mineral precipitation/dissolution or other types of chemical kinetics are considered.

Equilibrium constants rather than free energies of formation are used to define thermodynamic equilibrium. Standard Debye-Hückel activity coefficients are used to calculate species activities from species concentrations.

The treatment of adsorption is based on the fundamental relationship:

$$
B_{i}^{y}=K_{i}^{y}\left(\prod_{k=1}^{N} X_{k}^{a_{i}^{y}}\right)\left(\prod_{k=1}^{N} Y_{k}^{b_{k}^{y}}\right), i=1,2, \ldots, M_{y}
$$

where $B_{i}^{y}$ is the activity of the $\mathrm{i}$-th adsorbed surface species, $K_{i}^{y}$ is the equilibrium constant of the $\mathrm{i}$-th adsorbed species, $X_{k}^{a_{i}^{y}}$ is the activity of the k-th aqueous component species, $a_{i k}^{y}$ is the stoichiometric coefficient of the k-th aqueous component in the i-th adsorbed species, $Y_{k}^{b_{k}^{k}}$ is the activity of the $\mathrm{k}$-th adsorbed species, and $b_{i k}^{y}$ is the stoichiometric coefficient of the $\mathrm{k}$-th aqueous component in the i-th adsorbed species. The treatment uses the double layer theory to calculate activities of surface species (Davis \& Leckie, 1978).

Ion exchange is defined by the mass action expression:

$$
K_{i j}=\left(\frac{B_{i}}{A_{i}}\right)^{v_{j}}\left(\frac{A_{j}}{B_{j}}\right)^{v_{i}}, i=1,2, \ldots, M_{z}
$$

where $A_{j}$ is the activity of the $\mathrm{i}$-th aqueous species, $B_{j}$ is the activity of the $\mathrm{i}$-th ion-exchanged species, $v_{i}$ is the charge of the $\mathrm{i}$-th species, and $M_{z}$ is the number of ion exchanged species. It is difficult to derive simple analytical expression for anything but homovalent exchange. LEHGC can rigorously compute the Jacobian matrix for heterovalent ion exchange reactions.

It should be noted that the treatments of sorption and ion exchange are linked to a fictive sorbing compound or ion exchanger, and not to real minerals actively precipitating and dissolving during the reaction. The amount of sorbing compound or ion exchanger must be provided as input by the user. The code is not capable of linking the precipitation/dissolution process to sorption and ion exchange. For example, if during the reactive transport simulation, a zeolite phase were to precipitate, the code would not apply appropriate ion exchange properties to that mineral precipitate for the corresponding mass of precipitate. This type of scenario could not be rigorously modeled in 
one step with the LEHGC code. However, reasonable approximations could be generated using a carefully chosen sequence of simulations.

The most recent version of LEHGC provides for multiple surface complexation and ion exchange sites. It also provides for colloid transport although there is not yet any documentation to describe how it is implemented.

III. Coupling: The hydrologic and chemical constraints are coupled using the direct substitution approach. In this approach the chemical equilibrium equations are substituted into the hydrologic transport equations to result in a set of nonlinear partial differential equations. Different sets of dependent variables can be chosen for this approach (Yeh \& Tripathi, 1989). In LEHGC the total analytical concentrations of aqueous components are used as the dependent variables.

LEHGC does not currently provide for changes in matrix porosity/permeability with mineral precipitation/dissolution.

IV. Numerical Methods: The algorithm for solving the fluid flow problem is the finite-element Galerkin model in 2-D for an incompressible fluid. LEHGC solves the standard equations which relate pressure head, moisture content, and hydrologic conductivity. The solutions to these equations provide the temporal-spatial distribution of pressure head, moisture content, and the Darcy's velocity. No adaptive girding is currently coded.

V. Other Topics: Because LEHGC is an updated version of HYDROGEOCHEM, much of the documentation for HYDROGEOCHEM and its hydrologic modeling code predecessors (FEMWATER and FEMWASTE) apply to LEHGC. However, there is currently no comprehensive manual for LEHGC and it is difficult to determine exactly what changes have been made in developing LEHGC from these earlier codes.

Some verification and validation work has been performed using HYDROGEOCHEM (Yeh \& Tripathi, 1990) and LEHGC (Siegel et al., 1993, Siegel, 1993). This work has demonstrated that the ion exchange and sorption modules can correctly simulate some simple ion exchange and sorption experiments.

The development plan for LEHGC includes developing capabilities to more rigorously model unsaturated conditions, heat transport, and full 3D capabilities.

PRECIP: (Noy, 1991). This code was originally developed for modeling dissolution and precipitation reactions accompanying fluid flow in hot, dry rock geothermal systems. It was later employed for modeling mineral evolution in hyperalkaline systems (Clark et al., 1992; Khoury and 
Milodowski, 1992) and for modeling cement pore fluid chemistry (Savage et al., 1992; Savage and Rochelle, 1993). Its emphasis is on reaction relationships and phase equilibria, rather than on hydrological properties.

L. Fluid Flow: The code does not compute heat transfer, although calculations can be done in either an isothermal system, or one in which a temperature gradient exists along the flow path. The code does deal with mass transfer. The user defines an hydraulic head gradient for the system, which will thus control the computed Darcy velocities, given the other system properties. Only single-phase systems are considered. The transport and reaction equations are fully coupled and solved simultaneously. Hence, via a user-defined porosity-permeability relationship, full account can be taken of changes in hydrological properties on mass transport. The code only considers a porous medium, the properties of which may evolve through time as reaction proceeds, but it does not have the capability to deal with dual porosity systems. The assumption is made that the system under consideration is a single phase, fully saturated system. Humidities are not a relevant part of the calculations. The stress state is not considered in the calculations.

II. Chemistry; Reaction kinetics are incorporated as a function whose rate is dependent upon the saturation ratio. The general form of the equation considered in the code is

$$
\text { Rate }=\mathrm{ak}\left(\mathrm{W}^{\mathrm{m}}-1\right)^{\mathrm{n}}
$$

where $a$ is the effective surface area of the mineral, $k$ is the rate constant, and $W$ is the saturation ratio which is defined as the activity product $(Q)$ divided by the equilibrium constant $(K)$ for the reaction. The exponents $\mathrm{m}$ and $\mathbf{n}$ are reaction specific constants. Although specific values for these exponents have been incorporated in the code, user-defined values can be added, as can other userdefined rate functions. Temperature-dependence of the rate is incorporated into the rate constant, and in the function that describes $W$.

The reactions to be considered are hydrolysis reactions for the solids of interest, and these are directly incorporated into the code. Total mass of each component is accounted for in mass conservation equations that include the kinetic expressions for each phase, as well as longitudinal dispersivity and pore water diffusion terms. Incorporation of terms for porosity in these conservation equations then allows solution of the hydrologic and chemical conditions simultaneously, as a function of kinetics. Sorption and ion exchange are not considered.

The code relies on user-defined reactions to describe the rates of reactions, and reaction stoichiometry. The net reaction, defining the speciation state for each species, is determined from the sum of the hydrolysis reactions. Temperature dependence of the reactions is accounted for via the rate expressions described above. Activity coefficient models are not employed in the code. 
Thus, activity-composition relationships are not defined. Either activity can be assumed to be equivalent to concentration, or user-defined routines can be used to compute these. As the code currently exists, computational results are presented as concentrations.

III. Coupling: The code computes changes in porosity, based on volume changes due to precipitation or dissolution of solids. To translate porosity change into a change in permeability, a user-defined function must be added to the code; such a function is not explicitly incorporated into the code, as supplied. Nevertheless, the chemical, transport and dissolution and precipitation effects are solved simultaneously, thus avoiding the common difficulty of sequential calculations for transport and chemistry.

V. Numerical Methods: The code is solely one-dimensional. Simulations of mineralogical systems are done on the scale of millimeters or microns, to meters. The actual scale is determined by the flow velocity, and reaction rates, of the system under examination.

V. Other Topics: Documentation describing application of the code to different problems has been published. Code development is continuing. Verification and validation activities have taken the form of published applications of the code (described above). Some experiments are planned to test the simulations.

STELE: (Coudrain-Ribstein and Morel, 1987; Coudrain-Ribstein et al., 1989a, b; CoudrainRibstein and Marsily, 1989; Madé and Jamet, 1993a). This code was constructed by merging the transport code METIS (Goblet, 1989), with the chemical transport code CHIMERE (CoudrainRibstein and Jamet, 1989). STELE (or its component parts) has been applied to model the evolution of sedimentary basins (Coudrain-Ribstein and Marsily, 1989), evolution of aquifers in which hydrothermal fluids have been injected (Coudrain-Ribstein et al., 1989a, b; CoudrainRibstein and Gouze, 1993), uranium transport in soils (Jamet et al., 1993), and ore formation in Mississippi Valley type ore deposits (Schmitt et al., 1991). It has also been employed in the code comparison exercises of the Chemval project (Madé and Jamet, 1993b).

L. Fluid Flow: There is currently no capability to account for boiling, condensation, or two-phase flow. Heat and mass transfer are computed under conditions assuming complete saturation. Heat transfer is treated via the temperature dependence of the dynamic fluid viscosity, described by the Bingham formula (Madé and Jamet, 1993a), and by taking into account dispersion and convection during fluid flow. Darcy velocities are computed using 


$$
\mathrm{V}=\left(\mathrm{k} / \mathrm{m}_{\mathrm{d}}\right)(\operatorname{grad} \mathrm{P}+\mathrm{m} \operatorname{grad} \mathrm{z})
$$

where $k$ is the intrinsic permeability $\left(\mathrm{m}^{2}\right), \mathrm{m}_{\mathrm{d}}$ is the fluid viscosity $(\mathrm{kg} / \mathrm{m} \mathrm{s}), P$ is the pressure $\left(\mathrm{kg} / \mathrm{m} \mathrm{s}^{2}\right), r$ is the mass per unit volume of fluid, $\mathrm{n}$ is the gravitational constant $\left(9.91 \mathrm{~m} / \mathrm{s}^{2}\right)$, and $z$ is the vertical distance (m). Since boiling is not considered, only liquid velocities are considered. Dual porosity conditions are considered. Stress is not considered.

II. Chemistry: Reaction kinetics are treated using the rate law

$$
\Omega=(1 / \mathrm{dl})\left(\operatorname{TOT}_{1}\left(\mathrm{~B}_{\mathrm{j}}\right)-\mathrm{TOT}_{0}\left(\mathrm{~B}_{\mathrm{j}}\right)\right),
$$

where $\Omega$ is the geochemical flux (mol/Ls), dl is a kinetic term (s), TOT $1 \mathrm{~B}_{\mathrm{j}}$ ) is the concentration of component $\mathrm{Bj}$ at equilibrium with some mineral phase, and $\mathrm{TOT}_{0}\left(\mathrm{~B}_{j}\right)$ is the total aqueous concentration of $B_{j}$. This expression reduces to the classic relationship for reaction kinetics when considering only single phases

$$
\Omega=k_{c}(1-(Q / K))
$$

where $\mathrm{k}_{\mathrm{c}}$ is the rate constant, $\mathrm{Q}$ is the activity product, and $\mathrm{K}$ is the equilibrium constant. Further development of this portion of the code would be useful, to take into account the current state-ofthe-art.

Sorption can be treated using a partition coefficient approach, defined by Kd values.

Speciation calculations are done using a user-selected thermodynamic data file. Two activity coefficient models (Davies or Bromley; Madé and Jamet, 1993a) can be used. Saturation and precipitation or dissolution conditions are determined using standard mass action laws, employing the selected activity coefficient models. There is no limit to the number of species considered.

III. Coupling: Hydrological properties are assumed to remain constant throughout a simulation. There is no capability for updating porosity, permeability, or mechanical properties as dissolution or precipitation occurs in the currently available versions of the code. Mass transfer is assumed to occur under constant volume conditions. Hence, there is no coupling between mass transfer and changes in hydrological properties. Deposition and dissolution of material is treated as a bulk process in which moles of material are deposited or removed per meter $^{3}$ of porous media.

IV. Numerical Methods: All computations are two-dimensional, using an orthogonal finite element girding scheme. Adaptive girding is not employed, although non-uniform girding is possible. The code is designed to conduct simulations on the scale of meters to kilometers. The primary application has been in the study of basin and ore deposit development, evaluating flow regimes in hydrothermal systems. 
Y. Other Topics: Adequate documentation exists as users manuals (in French), and numerous publications describing application of the code to different problems. These applications constitute a verification effort. It has also been extensively employed in the Chemval project, which represents an international verification and validation activity.

\section{COMMENTS}

It is clear that no single code currently satisfies all of the potential modeling needs the project has. Code development and/or modification of codes will be necessary to obtain simulation capabilities required for Technical Site Suitability and License Application needs. However, the specific development or modification activity that needs to be undertaken will depend upon the codes selected for use. Test cases will be developed that can be used for all of the codes, and the results compared. From these results, a few codes will be selected for development/modification and use. The criteria to be used in selecting the codes will be developed next. The companion paper that describes and prioritizes modeling needs (Glassley et al., 1995, in prep.) should be consulted for a further description of selection criteria. 
References

Bethke, C. M. (1985). A numerical model of compaction-driven groundwater flow and heat transfer and its application to the paleohydrology of intracratonic sedimentary basins. Journal of Geophysical Research, 90, 6817-6828.

Bethke, C. M. (1986). Hydrologic constraints on genesis of the Upper Mississippi Valley Mineral District from Illinois Basin brines. Economic Geology, 81(81), 233-249.

Bethke, C. M., Harrison, W. J., Upson, C., \& Altaner, S. P. (1988). Supercomputer analysis of sedimentary basins. Science, 239, 261-267.

Bethke, C. M., Lee, M.-K., Quinodoz, H. A. M., \& Kreiling, W. (1993). Basin Modeling with Basin2. Urbana-Champaign: University of Illinois, UrbanaChampaign, $225 \mathrm{pp}$.

Brace, W.F. (1977), "Permeability From Resistivity and Pore Shape," J. Geoph. Res. 82, 33433349.

Buscheck, T. A., and J. J. Nitao (1992), The Impact of Thermal Loading on Repository Performance at Yucca Mountain, in Third International Conference on High Level Radioactive Waste Management, Las Vegas, American Nuclear Society, LaGrange Park, Ill., 1003-1017.

Buscheck, T. A., and J. J. Nitao (1993a), The Impact of Repository-Heat-Driven Hydrothermal Flow at Yucca Mountain, Lawrence Livermore National Laboratory, Livermore, Calif., UCRL-JC-112444.

Buscheck, T. A., and J. J. Nitao (1993b), The Impact of Repository Heat on ThermoHydrological Performance at Yucca Mountain, Lawrence Livermore National Laboratory, Livermore, Calif., UCRL-JC-114791.

Buscheck, T. A., and J. J. Nitao (1994), The Impact of Repository Heat on Hydrological Behavior at Yucca Mountain, Lawrence Livermore National Laboratory, Livermore, Calif., UCRL-JC-115798.

Camp, T.R. (1964), "Theory of Water Infiltration," J. Am. Soc. Civ. Eng. 90, 1-3.

Clark, I.D., H.N. Khoury, E. Salameh, P. Fritz, H.K. Seidlitz, and T.E. Milodowski (1992), "Origin of the Maqarin, Jordan, Hyperalkaline Groundwaters: Isotopic and Geochemical Evidence For In Situ Combustion, Calcination and Recarbonation of Bituminous Marls", in .Y.K. Kharaka and A.S. Maest (eds) Water-Rock Interaction. Balkema, Rotterdam, 14851489.

Coudrain-Ribstein, A. and P. Gouze (1993), "Quantitative Study of Geochemical Processes in the Dogger Aquifer, Paris Basin, France" Applied Geochemistry, 8, 495-506. 
Coudrain-Ribstein, A. and P. Jamet (1989), "Choix des Composantes et spéciation d'une solution." C.R. Acad. Sci. Paris, t. 309, série II, 239-244.

Coudrain-Ribstein, A., and G. de Marsily (1989), "Modeling of Mass Transfer Arising From Buoyancy Flow in Sedimentary Basins, Sci. Geol. Bull., 42, 299-312.

Coudrain-Ribstein, A. and F.M.M. Morel (1987), "Modélisation du transfert d'éléments majeurs réactifs dans un champ de température variable: méthodologie et exemples simples," Bull. Soc. Geol. France, 8, 1009-1017.

Coudrain-Ribstein, A., P. Goblet, and G. de Marsily (1989a), "Coupled Modeling of Flow, Mass Transport, Heat Transport and Chemistry: An Example. In H.E. Kobus and W. Kinzelbach (eds) Contaminant Transport in Groundwater. Balkema, Rotterdam, 173-177.

Coudrain-Ribstein, A., A. Vinsot, and P. Iris (1989b), "Space and Time Evolution of the Geochemical Processes Arising From Geothermal Injection in an Áquifer," Geothermics 18, 57-64.

Davis, J. A., \& Leckie, J. C. (1978). Surface ionization and complexation at oxide water interface, part 2. Journal of Colloid and Interface Science, 67, 90-107.

Glassley, W. E. (1993), Coupled Hydro-Geochemical Processes and Their Significance for Yucca mountain Site Characterization, in Proceedings of the ANS Topical Mtg. on Nuclear Waste Isolation in an Unsaturated Zone, Focus '93 (American Nuclear Society, La Grange Park, IL), p.221-224.

Goblet, P. (1989), "Programme METIS, Notice de Conception", ENSMP Technical Report 89/23, $124 \mathrm{p}$.

Jamet, P., P.J. Hooker, J.M. Schmitt, E. Ledoux, and P. Escalier des Orres (1993), "Hydrogeochemical Modeling of an Active System of Uranium Fixation by Organic Soils and Sediments (Needle's Eye, Scotland)", Mineral. Deposita 28, 66-76.

Kee, R.J., Petzold, L.R., Smooke, M.D., and Grcar, J.F., 1985, Implicit methods in combustion and chemical kinetics modeling, in Brackbill, J.U. and Cohen, B.I., eds., Multiple Time Scales: Academic Press, New York, p. 113-144.

Keith, L.A., P.T. Delaney and D.E. Moore (1983), "Permeability Reduction Due To Precipitation of Quartz Under Nonisothermal Conditions", in Ninth Workshop on Geothermal Reservoir Engineering, Stanford Univ., Stanford, CA.

Knapp, R.B. (1989), A Lagrangian Reactive Transport Simulator with Successive Paths and Stationary-States: Concepts, Implementation and Verification, Lawnence Livermore National Laboratory, Livermore, Calif., UCRL-100952.

Khoury, H.N. and T.E. Milodowski (1992), "High Temperature Metamorphism and Low Temperature Retrograde Alteration of Spontaneously Combusted Marls: The Maqarin 
Cement Analogue, Jordan", in Y.K. Kharaka and A.S. Maest (eds) Water-Rock Interaction. Balkema, Rotterdam, 1515-1518.

Krupp, R.E. and T.M. Seward (1987) "The Rotokawa geothermal System, New Zealand: An Active Epithermal Gold-Depositing Environment," Econ. Geol. 82, 1109-1129.

Lichtner, P.C. (1988), "The Quasi-Stationary State Approximation to Coupled Mass Transport and Fluid-Rock Interaction in a Porous Medium," Geochim. Cosmochim. Acta 52, 143-165.

Lichtner, P.C., 1992, Time-space continuum description of fluid/rock interaction in permeable media: Water Resour. Res., 28, p. 3135-3155.

Lichtner, P.C. (1993), "Scaling Properties of Time-Space Kinetic Mass Transport Equations and the Local Equilibrium Limit," Amer. Jour. Sci. 293, 257-296.

Lin, W. and W.D Daily (1989), "Laboratory Study of Fracture Healing in Topopah Spring Tuff Implications for Near Field Hydrology," in Proceedings of the ANS Topical Mtg. on Nuclear Waste Isolation in an Unsaturated Zone, Focus '89 (American Nuclear Society, La Grange Park, IL), p. 443

Made, B. and P. Jamet, (1993a), Modelling of Hydrothermal Systems with Coupled Chemical Reactions-Transport Code, in Proceedings of the 4th International Symposium on Hydrothermal Reactions, M. Cuney and M. Cathelineau, eds., Nancy, France, 139-142.

Madé, B. and P. Jamet, (1993b), Commisariat al'Energie Atomique CHEMVAL 2, Centre D'Informatique Geologique, Laboratoire D'Hydrogeologie Mathematique, Ecole Nationale Superieure Des Mines De Paris, $101 \mathrm{p}$.

Marsily, G. de, 1986, Quantitative Hydrogeology: Academic Press, New York, 440 p.

McClure, L.C., H.S. Fogler and W.E. Kline (1979), "An Experimental Technique for Obtaining Permeability-Porosity Relationships in Acidizing Porous Media," Ind. Chem. Eng. Fundam. 18, 188-191.

Moore, D.E., C. Morrow and J. Byerlee (1986), "High Temperature Permeability and Groundwater Chemistry of Some Nevada Test Site Tuffs," J. Geoph. Res. 91, 2163-2171

Morrow, C., D. Lockner, D. Moore, and J. Byerlee (1981). "Permeability of Granite in a Temperature Gradient," J. Geoph. Res. 86, 3002-3008.

Noy, D.J. (1991), PRECIP: A Program for Coupled Groundwater Flow and Precipitation/Dissolution Reactions, British Geological Survey, Technical Report WE/90/38C, $37 \mathrm{pp}$.

Patankar, S.V., 1980, Numerical Heat Transfer and Fluid Flow:: Hemisphere Pub., New York, $197 \mathrm{p}$.

Pearson, R.O. (1976), Planning and Design of Additional East Mesa Geothermal Test Facilities (Phase 1B), I. Final Report, Sandia National Laboratory, NM, SAN/1140-1/1. 
Phillips, O.M., 1991, Flow and Reactions in Permeable Rocks: Cambridge Univ. Press, Cambridge, $277 \mathrm{p}$.

Phillips, S. L., Igbene, A., Fair, J. A., \& Ozbec, H. (1981). A Technical Databook for Geothermal Energy Utilization. (Report No. LBL-12810). Lawrence Berkeley Laboratory.

Pyrak-Nolte, L.J., L.R. Myer, N.G.W. Cook, and P.A. Witherspoon (1987), "Hydraulic and Mechanical Properties of Natural Fractures in Low Permeability Rock", in Sixth International Cong. on Rock Mechanics, Montreal, Canada.

Rimstidt, J.D. and W.D. Newcomb (1989), "A Vertical Thermal Gradient Experiment to Simulate Conditions in Vapor Dominated Geothermal Systems, Epithermal Gold Deposits, and High Level Radioactive Waste Repositories in Unsaturated Media," in Miles (ed.) Water-Rock Interaction, A.A. Balkeema, Rotterdam, 585-588.

Savage, D., K. Bateman, P. Hill, C. Hughes, A. Milodowski, J. Pearce, E. Rae, and C. Rochelle (1992), "Rate and Mechanism of the Reaction of Silicates with Cement Pore Fluids", Applied Clay Sci. 7, 33-45.

Savage D. and C.A. Rochelle (1993), "Modeling Reactions Between Cement Pore Fluids and Rock: Implications for Porosity Change", J. Contaminant Hydrology 13, 365-378.

Scheidegger, A. (1974), The Physics of Flow Through Porous Media, Macmillan, New York.

Schmitt, J-M., S. Makhoukhi, and P. Goblet (1991), "Modelling of Structure-Induced Hydrothermal Circulations in a Mississippi Valley Type Deposit". In, M. Pagel and J.L.Leroy (eds.), Source, Transport, and Deposition of Metals, Balkema, Rotterdam, 489492.

Siegel, M. D. (1993). "Towards a realistic approach to validation of reactive transport models for performance assessment." In Proceedings of FOCUS 93, Site characterization and model validation., . Las Vegas, Nevada: American Nuclear Society.

Siegel, M. D., Ward, D. B., Bryan, C. R., \& Hopkins, P. (1993). WBS 1.2.5.4.6 Development and validation of reactive transport models for performance assessment No. Sandia National Laboratory.

Steefel, C.I., 1993, 1DREACT: One-dimensional reaction-transport model: User manual and programmer's guide: unpub. manuscript, $42 \mathrm{p}$.

Steefel, C.I., and A. C. Lasaga (1992), "Putting Transport into Water-Rock Interaction Models," Geology 20, 680-684.

Steefel, C.I., and Lasaga, A.C., 1994, A coupled model for transport of multiple chemical species and kinetic precipitation/dissolution reactions with application to reactive flow in single phase hydrothermal systems: Amer. Jour.Sci., 294, p. 529-592. 
Steefel, C.I., and Lichtner, P.C., 1994, Diffusion and reaction in rock matrix bordering a hyperalkaline fluid-filled fracture: Geochim. Cosmochim. Acta, 58, p. 3595-3612.

Travis, B. J., S. W. Hodson, H. E. Nuttal, T. L. Cook, and R. S. Rundberg (1984), Preliminary Estimates of Water Flow and Radionuclide Transport in Yucca Mountain, Los Alamos National Laboratory, Los Alamos, NM, LA-UR-84-40 (Rev).

Vaughan, P.J. (1985), "Analysis of Permeability Reduction During Flow of Heated, Aqueous Fluid Through Westerly Granite," in International Symposium on Coupled Processes Affecting the Performance of a Nuclear Waste Repository, Lawrence Berkeley Laboratory, Sponsored by U.S. DOE, Sept. 18-20.

Verma, A. and K. Pruess (1988), "Thermohydrological Conditions and Silica Redistribution Near High-Level Nuclear Wastes Emplaced in Saturated Geological Formations," J. Geoph. Res. 93, 1159-1173.

Yeh, G. T., \& Tripathi, V. S. (1989). "A critical evaluation of recent developments in hydrogeochemical transport models of reactive multichemical components". Water Resources Research, 25(1), 93-108.

Yeh, G. T., \& Tripathi, V. S. (1990). HYDROGEOCHEM: A coupled model of HYDROlogic transport and GEOCHEMical equilibria in reactive multicomponent systems. (Report No. ORNL-6371). Oak Ridge National Laboratory.

Zyvoloski, G. (1983), "Finite Element Methods for Geothermal Reservoir Simulation," Int. J. Numer. Anal. Methods Geomech. 7, 75-86.

Zyvoloski, G. (1986), "Incomplete Factorization for Finite Elements," Int. J. Numer. Methods in Eng. 23, 1101-1109. [NNA.890523.0138]

Zyvoloski, G. and Z. Dash (1991), Software Verification Report FEHMN Version 1.0, Los Alamos National Laboratory, Los Alamos, NM, LA-UR-91-609.

Zyvoloski, G., Z. Dash and S. Kelbar, (1988), FEHM: Finite Element Heat and Mass Transfer Code, Los Alamos National Laboratory, Los Alamos, NM, LA-11224-MS. 


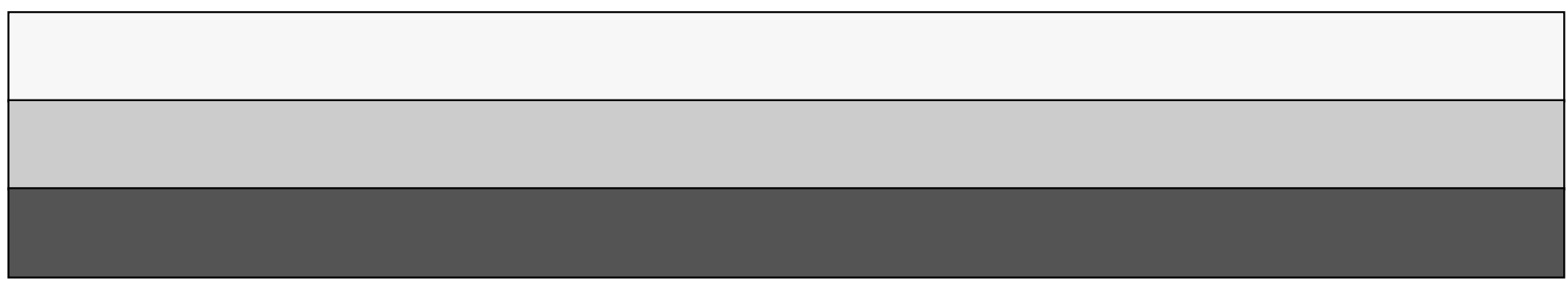

